Disclosure of Interests: None declared

DOI: 10.1136/annrheumdis-2021-eular.3155

\section{AB0897-HPR EVALUATION OF ANXIETY AND DEPRESSION IN PATIENTS WITH KNEE OSTEOARTHRITIS USING THE HAD “HOSPITAL ANXIETY AND DEPRESSION SCALE”}

M. Brahem ${ }^{1}$, S. Abdellatif ${ }^{1}$, H. Hachfi ${ }^{1}$, A. Ben Salem ${ }^{1}$, R. Sarraj ${ }^{1}$, R. Ben Tekaya ${ }^{1}$, Y. Mohamed ${ }^{1}{ }^{1}$ Taher Sfar Hospital, Rhumatology, Mahdia, Tunisia

Background: Knee osteoarthritis is considered to be one of the most common causes of functional impairment, which affects the quality of life of patients leading to severe mood disorders. Our goal is to evaluate the frequency of depression and anxiety in patients with knee osteoarthritis.

Objectives: Evaluate the frequency of depression and anxiety in patients with knee osteoarthritis.

Methods: This is a cross-sectional study over a period of 7 months from February to August 2016, including consecutively patients who consulted in the Rheumatology department at Mahdia university hospital for knee osteoarthritis We evaluated for each patient a validated version of HAD "Hospital Anxiety and Depression scale". This score includes 14 items each one rated from 0 to 3 and two components including depression and anxiety.

Results: We included in our study 66 patients (56 women and 10 men) with an average age of 60.3 years [ $40-90$ years]. Knee osteoarthritis was bilateral in $56.1 \%$ of cases. The examination found limited mobility of the knee in $45.5 \%$ and flessum in $13.8 \%$ of cases. Standard radiography showed stage 1 knee osteoarthritis in $4.5 \%$, stage 2 in $31.8 \%$, stage 3 in $56.1 \%$ and stage 4 in $7.6 \%$ of cases. All our patients were treated with analgesics, NSAIDs in $95.5 \%$, local corticosteroid infiltrations in $43.9 \%$ and hyaluronic acid in $7.6 \%$ of cases. The mean visual analog scale(VAS)was $5.84 \pm 1.7$ out of 10 [2-9]. The mean overall WOMAC index was $47.15 \pm 15.6$ [12-82]. The average Lequesne index was $16.8 \pm 13.1$, moderate disability was found in $3 \%$ of cases, significant disability in $6.1 \%$ of cases, very significant disability in $18.2 \%$ of cases and extreme disability in $72.7 \%$ of cases. The mean depression score was $9.3 \pm 2.6$ [4-16], with $24.6 \%$ of the patients had no depressive symptomatology (score $\leq 7$ ), $40 \%$ had doubtful depressive symptomatology (score between 8 and 10) and 35.4\% of them had certain depressive symptomatology (score $\geq 11$ ). The mean anxiety score was $8.88 \pm 4$ [0-19], 33.3\% of patients had no anxiety symptoms (score $\leq$ 7 ), $34.8 \%$ had doubtful anxiety (score between 8 and 10 ) and $31.8 \%$ had certain anxiety (score $\geq 11$ ). The statistical study found a significant correlation between the depression score and WOMAC score, but we did not find an association with age, sex, radiological stage, mobility limitation and VAS. Regarding anxiety, there was a correlation with age, WOMAC score and female gender. On the other hand, there was no correlation with VAS, Lequesne score, radiological stage and limitation of mobility.

Conclusion: Although knee osteoarthritis appears to be a benign pathology, its impact can be severe, including depression and anxiety, which are mainly influenced by the degree of functional disability. Hence psychological care is sometimes necessary in these chronic degenerative diseases.

Disclosure of Interests: None declared

DOI: 10.1136/annrheumdis-2021-eular.3835

\section{AB0898-HPR WICH FACTORS ARE RELATED TO PAINFUL EXPERIENCE IN PATIENTS AFFECTED BY CHRONIC INFLAMMATORY RHEUMATIC DISEASE DURING THE COVID-19 PANDEMIC?}

T. El Joumani ${ }^{1}$, H. Rkain ${ }^{1,2}$, T. Fatima Zahrae ${ }^{1}$, H. Kenza $^{3}$, R. Abouqal ${ }^{4}$ N. Laila ${ }^{5}$, S. Bahloul ${ }^{1}$, E. A. Nada ${ }^{1}$, T. Latifa ${ }^{1}$, N. Hajjaj-Hassouni ${ }^{6}$, F. Allali ${ }^{1}{ }^{1}$ El Ayachi Hospital, Faculty of Medicine and Pharmacy of Rabat, Mohammed V University, Rabat, Morocco, Department of Rheumatology B, Rabat, Morocco; ${ }^{2}$ Faculty of Medicine and Pharmacy of Rabat, Mohammed V University, Rabat, Morocco, Physiology Laboratory, Rabat, Morocco; ${ }^{3}$ Université Mohammed VI des Sciences de la Santé - UM6SS, Casablanca, Morocco., Ecole Internationale de Santé Publique, Rabat, Morocco; ${ }^{4}$ Faculty of Medicine and Pharmacy of Rabat, Mohammed V University, Rabat, Morocco, Laboratory of Biostatistics, Rabat, Morocco; ${ }^{5}$ Moroccan Association of Patients With Rheumatoid Arthritis and Spondyloarthritis, Rheumatology, Rabat, Morocco; ${ }^{6}$ International University of Rabat, Rabat, Morocco, Rheumatology, Rabat, Morocco

Objectives: To evaluate the effect of containment, during the Covid-19 pandemic, on the pain of patients with CIRD, and to analyze the factors associated with the experience of pain.

Methods: A cross-sectional study was conducted among patients with rheumatic diseases using a questionnaire providing information on patients and disease characteristics. Impact of COVID-19 on This is a cross-sectional study that consecutively included
Patients were asked to assess the global pain which they had experienced before and during the containment period, using a single Visual Analogue Scale (VAS) ranging from 0 (no pain) to 10 (greatest pain).

Statistical Analysis System IBM SPSS Statistics V20.0.0 was used to analyze the study data.

We performed univariate then multivariate analysis to search any related factors to pain perception during to quarantines. Qualitative values were analyzed by the chi2 test. Quantitative values were analyzed by the Student test when the measures were normally distributed or by nonparametric test (Mann-Whitney $\mathrm{U}$ ) when the measures were not normally distributed (Kolmogorov-Smirnov test was used to test normality).

Results: Among the 350 patients who answered to the questionnaire online, rheumatoid arthritis represented $62.3 \%$, spondyloarthropathy $34.3 \%$ and undifferentiated CIRD $3.4 \%$

Pain experience caused by the CIRD during the containment was reported by $79.1 \%$ of patients.

The level of pain, using the VAS of Pain increased significantly during the COVID19 pandemic $(4,6 \pm 2,8$ and $5,4 \pm 3$ before and during the containment; $p<0.001)$ In multivariate analysis, the factors implicated in pain were the negative impact of Coronavirus on access to rheumatologic care, discontinuation of therapeutic adherence, the disturbed quality of sleep and the negative psychological impact (table 1).

Table 1: Summarize multivariable analysis of factors associated with painful experience related to CIRD during containement.

Table 1. Multivariable analysis of factors associated with painful experience related to CIRD during containement

\begin{tabular}{ll}
\hline & $\mathbf{P}$ \\
\hline Impact on monitoring & 0.05 \\
Impact on therapeutic adherence & $<0.001$ \\
Quality of sleep disturbed & 0.001 \\
Negative psychological impact & 0.02
\end{tabular}

Conclusion: This survey showed the that the COVID-19 pandemic have incresed painful experience in CIRD patients. Factors influencing painful experience should be taken into account to help patients to cope with their chronic rheumatism and this global health crisis.

Disclosure of Interests: None declared

DOI: 10.1136/annrheumdis-2021-eular.4073

\section{AB0899-HPR THE IMPACT OF CORONAVIRUS (COVID-19) PANDEMIC ON THERAPEUTIC MAINTENANCE IN PATIENTS WITH CHRONIC INFLAMMATORY RHEUMATIC DISEASES}

T. El Joumani ${ }^{1}$, H. Rkain ${ }^{1}$, T. Fatima Zahrae ${ }^{1}$, H. Kenza ${ }^{2}$, A. Radouan ${ }^{3}$ N. Laila ${ }^{4}$, S. Bahloul ${ }^{1}$, E. A. Nada ${ }^{1}$, T. Latifa ${ }^{1}$, N. Hajjaj-Hassouni ${ }^{5}$, F. Allali ${ }^{1}{ }^{1} E I$ Ayachi Hospital, Faculty of Medicine and Pharmacy of Rabat, Mohammed V University, Rabat, Morocco, Department of Rheumatology B, Rabat, Morocco ${ }^{2}$ Université Mohammed VI des Sciences de la Santé - UM6SS, Casablanca, Morocco., Ecole Internationale de Santé Publique, Rabat, Morocco; ${ }^{3}$ Faculty of Medicine and Pharmacy of Rabat, Mohammed V University, Rabat, Morocco, Laboratory of Biostatistics, Rabat, Morocco: ${ }^{4}$ Moroccan Association of Patients With Rheumatoid Arthritis and Spondyloarthritis, Rheumatology, Rabat, Morocco; ${ }^{5}$ International University of Rabat, Rabat, Morocco, Rheumatology, Rabat, Morocco

Background: The Coronavirus pandemic caused many consequences on well being, access to care and therapeutic maintenance in patients with chronic diseases.

Objectives: To assess the impact of COVID-19 on therapeutic maintenance of patients with Chronic Inflammatory Rheumatic Diseases (CIRD) and to identify related factors to difficulties in access to rheumatologist care during the COVID19 pandemic

Methods: A cross-sectional study was conducted among patients with rheumatic diseases using a questionnaire providing information on patients and disease characteristics, impact of COVID-19 on access to rheumatologist care and therapeutic maintenance during the confinement. Reasons of therapeutic interruption and of diificulties in access to healthcare were precised.

Results: We received answers from 350 patients (female sex of $68 \%$, mean age of $46,1 \pm 14,4$ years) suffering from Chronic Inflammatory Rheumatic Diseases (CIRD):rheumatic arthritis (RA) (62.3\%), spondyloarthropathies (34.3\%), and undifferentiated CIRD (3.4\%). The global average disease evolution was 12,1 $\pm 9,7$ years.

The patients were treated with conventional Disease-modifying anti-rheu matic drugs (cDMARDs) and biologic Disease-modifying anti-rheumatic drugs 
(bDMARDs) in respectively $67.4 \%$ and $30.6 \%$ of cases. Corticosteroids and Nonsteroidal Anti-Inflammatories (NSAIDs) intake was noted in 39.1 and $33.7 \%$ of patients.

Difficulties to access to rheumatologist care appointments were reported in $82.9 \%$ of the participants. Reasons of thoses difficulties are summurized in Figure 1.

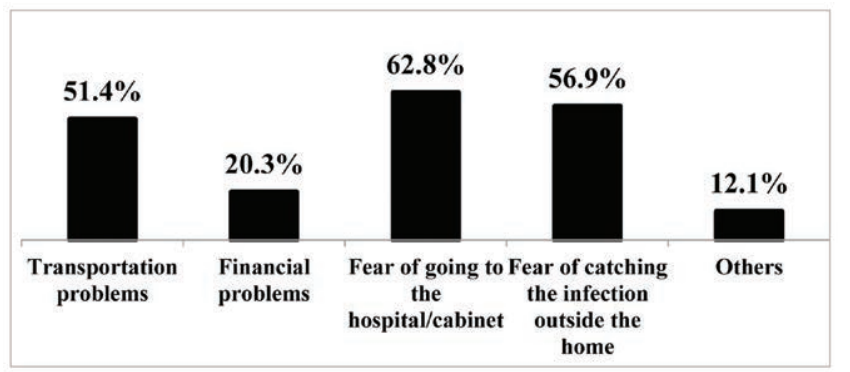

Figure 1. Causes of difficulties of access to Rheumatologist care during COVID-19 pandemic.

Half of patients declared that the pandemic had affected their therapeutic compliance. Discontinued drugs were in decreasing order: Synthetic antimalarials $(68.4 \%)$, NSAIDs (45.8\%), Methotrexate (43.8\%), bDMARDs (25.2\%), Sulfasalazine (18.2\%) and Corticosteroids (10,2\%).

Causes of treatments interruption are summarized in Table I.

Table 1. Causes of treatments interuption in patients with CIRD

\begin{tabular}{|c|c|c|c|c|c|}
\hline Drugs & $\begin{array}{l}\text { Not } \\
\text { found in } \\
\text { pharma- } \\
\text { cies }\end{array}$ & $\begin{array}{l}\text { The pharmacy } \\
\text { refuses to give } \\
\text { me the treatment } \\
\text { without a recent } \\
\text { prescription }\end{array}$ & $\begin{array}{l}\text { To avoid the } \\
\text { decrease in immu- } \\
\text { nity and therefore } \\
\text { to avoid catching } \\
\text { Covid-19 }\end{array}$ & $\begin{array}{l}\text { I stopped the } \\
\text { follow-up, } \\
\text { and so I } \\
\text { stopped the } \\
\text { treatment... }\end{array}$ & $\begin{array}{l}\text { Other } \\
\text { reasons }\end{array}$ \\
\hline NSAIDS & 0 & 27.8 & 74.1 & 44.4 & 27.8 \\
\hline Corticosteroids & 0 & 14.3 & 92.9 & 57.1 & 50 \\
\hline Methotrexate & 70.1 & 3 & 10.4 & 16.4 & 22.4 \\
\hline Sulfasalazine & 0 & 12.5 & 25 & 75 & 100 \\
\hline $\begin{array}{l}\text { Synthetic } \\
\text { antimalarial }\end{array}$ & 69.2 & 0 & 0 & 23.1 & 61.5 \\
\hline Leflunomide & 0 & 0 & 0 & 0 & 0 \\
\hline bDMARDs & 0 & 7.4 & 40.7 & 44.4 & 51.9 \\
\hline
\end{tabular}

Conclusion: The COVID-19 pandemic impacted heavly on therapeutic maintenance in CIRD patients in our country. Patients expressed many difficulties in access to appropiate management. Facing to all thoses consequences, we need to devolopp as soon as possible adequate solutions adapted in such health crisis, especially therapeutic education and telemedecine.

Disclosure of Interests: None declared

DOI: 10.1136/annrheumdis-2021-eular.4151

\section{AB0900-HPR THE EXPECTATIONS AND EXPERIENCES OF PATIENTS WITH RHEUMATOID ARTHRITIS AFTER ENROLLING INTO AN EDUCATIONAL PROGRAM. RESULTS FROM A MIXED STUDY APPROACH}

R. A. Castiblanco Montañez ${ }^{1}$, A. Arevalo Velandia ${ }^{1}$, J. D. Garzon Cepeda ${ }^{1}$, F. Rodriguez-Florido ${ }^{2}$, D. Buitrago-Garcia ${ }^{1}$, G. Sánchez ${ }^{1}$, P. Santos-Moreno ${ }^{2}$. ${ }^{1}$ Fundación Universitaria de Ciencias de la Salud FUCS. Sede Centro, Bogotá, Bogotá, Colombia; ${ }^{2}$ Biomab IPS, Bogotá, Bogotá, Colombia

Background: Rheumatoid arthritis (RA) is a high-cost disease, usually diagnosed at a productive age in life. RA brings significant changes in a patient's life. On an emotional level, the patient perceives a strong impact that generates disorientation, denial, depression, hopelessness, anger and fear due to the uncertainty of the development of the disease and the doubt of the turn that his life will take. However, each patient has different ways of coping with the disease and adapting to it $(1,2)$. These changes require attention from health personnel. In this regard, different studies have reported the effect of educational, support and empowerment programs for patients on reducing the effects of the disease and the benefits are oriented towards improving lifestyles by improving self-care $(3,4)$. Objectives: To describe the experience of patients with rheumatoid arthritis, their perception and expectations about entering a multicomponent educational program in a specialized center in Bogotá - Colombia.

Methods: For this study a concurrent mixed design was used, in which quantitative and qualitative methods are applied simultaneously, we invited patients with rheumatoid arthritis who attended a specialized center in Bogotá - Colombia who enrolled in an education program called UNIVERSITAR. The quantitative phase included a descriptive analysis and the application of the expectations scale adapted from Borkovec and $\mathrm{Nau}(5)$; this scale collects information about the level of expectations and satisfaction of the program. The scale ranges from 0 (not at all) to 10 (very much). Immediately after the application of the scale, the participants were invited to a focus group that allowed the dialogue on the perception and expectations of the participants regarding the program, through a dynamic process in which the participants exchanged their ideas and opin ions. A group interview script was used, aimed at identifying the patients' experiences with their diagnosis and their expectations regarding the program. Two focus groups were held with an average duration of one hour; the discussion was recorded on audio and transcribed in its entirely.

Results: We included 31 participants and were distributed in two focus groups The median age of the participants was 60 years IQR (54-67), 92\% were female. $77 \%$ of participants reported high scores for the satisfaction regarding the program. In the qualitative phase two categories emerged that speak of the experience of the participants with the disease. They highlighted the appearance of this disease in their lives in an unexpected way, the doubts and uncertainties that were generated from the diagnosis and the implications that this condition causes health in their everyday life. However, in the second category, the expectations and motivations of the participants towards the educational program are highlighted, and the factors that influence their participation and their motivation to train and empower themselves to make decisions and as expert patients, capable of educate, guide and support other patients with the same diagnosis. Conclusion: The expectations and perceptions of the patients are of great importance, since through these the conditions with which these educational programs provide interventions and a better quality of life to these patients can be improved. Disclosure of Interests: None declared

DOI: 10.1136/annrheumdis-2021-eular.4160

\section{AB0901-HPR SOCIAL AND PSYCHOLOGICAL IMPACT OF THE CONTAINEMENT DURING COVID-19 PANDEMIC ON PATIENTS WITH CHRONIC INFLAMMATORY RHEUMATIC DISEASES}

T. El Joumani ${ }^{1}$, H. Rkain ${ }^{1}$, T. Fatima Zahrae ${ }^{1}$, H. Kenza ${ }^{2}$, A. Radouan ${ }^{3}$, N. Laila ${ }^{4}$, S. Bahloul ${ }^{1}$, E. A. Nada ${ }^{1}$, T. Latifa ${ }^{1}$, N. Hajjaj-Hassouni ${ }^{5}$, F. Allali ${ }^{1}{ }^{1}$ El Ayachi Hospital, Faculty of Medicine and Pharmacy of Rabat, Mohammed V University, Rabat, Morocco, Department of Rheumatology B, Rabat, Morocco; ${ }^{2}$ Université Mohammed VI des Sciences de la Santé- UM6SS, Casablanca, Morocco., Ecole Internationale de Santé Publique, Rabat, Morocco; ${ }^{3}$ Faculty of Medicine and Pharmacy of Rabat, Mohammed V University, Rabat, Morocco, Laboratory of Biostatistics, Rabat, Morocco; ${ }^{4}$ Moroccan Association of Patients With Rheumatoid Arthritis and Spondyloarthritis, Rheumatology, Rabat, Morocco; ${ }^{5}$ International University of Rabat, Rabat, Morocco, Rheumatology, Rabat, Morocco

Background: Covid-19 pandemic had a worldwide impact on the population global economy and health care systems.

Objectives: To evaluate the psychological state and social impact of patients with Chronic Inflammatory Rheumatic Diseases (CIRD) during this pandemic in order to understand how to optimize their quality of life.

Methods: It's a cross-sectional survey, where the data were collected through the online survey tool "google forms". A pilot test were conducted with the study committee members who analyzed the apparent validity of the questionnaire and identified issues that could lead to misunderstandings, and their suggestions were refined by a retest reliability until general agreement.

The social and psychological impacts were evaluated by 14 questions exploring the different effects of the containment on negative feelings, interest in the family, changes in daily activities and plans, quality of sleep, practice of physical activity before and during containment, as well as the impact of the Coronavirus on psychological health. Statistical Analysis System IBM SPSS Statistics V20.0.0 was used to analyze the survey data.

Results: 350 patients had participated in this online survey (mean age of 46,1 $\pm 14,4,68 \%$ were women, $15.7 \%$ were illiterate, $45.7 \%$ were unemployed, rural residence in $11.7 \%$ of cases).

Patients reported that their mental health has been negatively affected by Coronavirus in $59.1 \%$ of cases. Table 1 summarizes the psychological events during the containment.

Table 1. Negative feelings during the containment

\begin{tabular}{lc}
\hline Negative feelings (\%) & $\mathrm{N}=\mathbf{3 5 0}$ \\
\hline Hopelessness & 23.7 \\
Anxiety & 55.4 \\
Fear & 29.7 \\
Frustration & 22.9 \\
Loneliness & 17.4 \\
Anger & 22.6 \\
Powerlessness & 24.3
\end{tabular}

Patients reported that they paid more attention to their family in $87.1 \%$ during containment. Their daily lives and their life plans had changed because of 